treatment by drugs and diet to a practical basis; that is, judged from the standpoint of the success which attended and continues to attend treatment based on those lines, which are practically identical with, and are an elaboration of, Dr. Sharp's experiences.

I am, Sirs, yours faithfully,

F. W. Forbes Ross, M.D. Edin., D.P. H. Lond. Gower-street, London, W.C., Nov. 9th, 1902.

\section{THE MEDICAL DEFENCE UNION.}

\section{To the Editors of THE LANCET.}

SIRs,--In answer to Mr. Percy Rose I have to state that the matter of imposing an entrance fee to all new subscribers to the Medical Defence Union joining on and after Jan. 1st, 1903 , is not one for discussion by the members at the annual meeting as the power to impose such entrance fee is granted to the council alone by the articles of association. 'To raise the subscription is a matter requiring the consent of members at a general meeting assembled, but the entrance fee is one solely for council to decide. The payment required including the entrance fee is so small and the benefits which may be derived should occasion require are so large that it is impossible to imagine that the amount to be asked for on and after Jan. 1st will prevent men from insuring. Considering that all medical societies of any note charge $£ 11 s$. per annum for the privilege of "discussion and hearing papers," 10s. a year for membership of the Medical Defence Union is very little. I may mention that the entrance fee was decided upon by the council after long and careful consideration and that the notice given is more than ample for every member of the profession in Great Britain and Ireland to apply for membership of the Union before Jan. 1st, 1903, on the old terms.

I am, Sirs, yours faithfully,

A. G. BAteman, General Secretary.

Trafalgar-square, W.C., Nov. 10th, 1902.

\section{DEATH UNDER CHLOROFORM. \\ To the Editors of THE LANCET.}

Sirs,-In the fatal case after chloroform which occurred at Guy's Hospital on Oct. 23rd the statement was made that the patient had only been given one and a half drachms of the anæsthetic. This shows that the death was not due to an excessive amount of chloroform having been administered. In a very able paper published last year Sir W. Mitchell Banks of Liverpool pointed out that the path of safety lay in following out the dictum, "Plenty of air, plenty of chloroform." This advice is not being followed in many quarters and professional anæsthetists are wasting their ingenuity in seeing by how little chloroform they can accomplish their end. Every physiologist knows that the brain cells require a constant supply of oxygen as they are unable to keep a store of it locked up for any considerable time, being rather unstable. Now, in order to accomplish anæsthesia on a minimum of chloroform the supply of oxygen must be curtailed very much. The fad for this accurate measurement of chloroform is ridiculous for another reason-namely, that a healthy baby will often take as much as a full-grown person.

\section{I am, Sirs, yours faithfully}

A. W. FULLER, M. B. Edin., \&c.

Royal Hospital for Children and Women, S.E., Oct. 25th, 1902.

** Our correspondent has overlooked an important point among others. All familiar with the action of chloroform are aware that a drachm or far less given without adequate dilution will cause death. Sir W. Mitchell Banks's dictum, which is almost a verbal repetition of Syme's, refers solely to the wholly untrustworthy method unhappily still commonly employed and called the "open method." Death from chloroform arises from the action of that drug upon the nervous tissue of the medullary centres and not from deprivation of oxygen, although nerve tissues the oxygen tension of which is lowered are more prone to chloroform destruction. The "fad" for accurate measurement of chloroform is on a parity with the attempt among all truly scientific persons to know what quantities of powerful poisons they are using in order that they may graduate their doses to the requirement of their patient. We have yet to meet the baby who, if accurately chloroformed, will require as much as a full-grown person.-ED. L.

\section{THE ROYAL MEDICAL BENEVOLENT COLLEGE. \\ To the Editors of THE LANCET.}

SIRs,--With reference to Dr. C. Holman's appeal on behalf of the above the following may seem to you not without interest to the profession at large. Some three years ago I was asked to fill the post of honorary local secretary in a district with some 70,000 inhabitants. I wrote to all medical men in the district whose names could be ascertained, and to some of the leading inhabitants of all denominations, urging the need of support, some 60 to 70 letters in all. With the exception of two or three letters of regret from personal medical friends I had no replies whatever. The following year I wrote to medical men only, personally known to me, asking for a donation or subscription of $5 s$.; two verbal expressions of regret.

Is not the apathy of medical men in this matter due to the overcrowded state of this as of all other callings? In suburban practice, when every newly qualified diplomate is Dr. - - physician and surgeon, and many are ready to undertake the medical care of a family of four at $9 d$. a month, we cease, as a class, to deserve to be called professional and become commercial. Hence, while we cultivate a cutting trade, we forfeit the status of our forefathers and correspondingly sink in the estimation of the public, our relation with our patients becomes purely on a trade basis. Why should they support a medical benevolent fund? On the other side many medical men finding their hand forced are obliged to meet competition, they do more work for less return and have no longer means to help.

Your return of new entries at medical schools shows a decided decrease, and it is a well-known fact that many medical men have within the last few years given up general practice for dentistry.

I am, Sirs, yours faithfully,

B. Faradar Giles, M.D. Durh.

Church-lane, Hornsey, N., Nov. 3rd, 1902.

\section{THE TUNING-FORK AS AN AID IN DIAGNOSIS.}

To the Editors of THE LANCET.

SIRs, - As the adequate treatment of disease is only possible when the diagnosis is correct, any aid to diagnosis is a matter of supreme importance. In Trre LANCET of Oct. 11th, p. 991, I read with interest Dr. G. M. de la Torre's article on unilateral pressure as a means of diagnosis in inflammatory conditions of the pulmonary organs. It has encouraged me to mention an additional aid which $I$ have lately used in my own practice and one which, it appears to me, is capable of considerable development. The tuning-fork has been long regarded as being of as much diagnostic importance to the aural surgeon as the stethoscope is to the physician. With the intelligent coöperation of the patient, however, it can be utilised to great advantage in general practice.

Patients suffering from pulmonary troubles-more especially in the earlier and convalescent stages-have frequently remarked that "when speaking they can hear or feel their own voices vibrating in the affected area," and this suggested to me experiments with the tuning-fork. I then found as an invariable rule that the vibrations of the tuning-fork were felt by the patient most distinctly when placed over a dull region, less distinctly when placed over an early or transitional dulness, and least over a healthy lung; I also found that with an intelligent patient it gave finer results than percussion. I further noticed that, though the differences were not so decidedly marked as in the preceding instances, on auscultating the back of the chest when the tuning-fork is placed over a corresponding part of the front of the chest it is more distinctly heard through healthy than through consolidated lung. This, too, was the reverse to the patient's own appreciation of the vibrations, the patient feeling them most over the dull part.

I have not yet had sufficient opportunity of testing the effect of the tuning-fork in cases of pleurisy with effusion, though in some slight cases which $I$ examined it appeared to me that the vibrations of the tuning-fork were less appreciated by the patient and by myself. This is a distinction to be noticed between this and the two preceding 
cases. To recapitulate : 1 . The patient feels the vibrations of the tuning-fork most when it is placed over a dull area. 2 . On auscultation the sounds are heard least when transmitted through consolidated lung. 3. The patient feels the vibrations least when the tuning-fork is placed over healthy lung. 4. On auscultation the vibrations are heard most clearly when transmitted through healthy lung. 5. In pleurisy with effusion the vibrations are more obscure to patient and physician alike. It is, of course, necessary that the tuning-fork should be vibrating when applied in the first instance to the different parts of the patient's chest with equal intensity. Later it may be passed from one area to the other without being freshly agitated-as in Rinne's test in aural diagnosis. 'The intelligence and acuteness of the patient are important matters to have in mind when making the diagnosis, yet when included in our calculations are not likely to lead to real error in this as in all other descriptions given by patients of symptoms and subjective phenomena.

A rough estimate of the varying distinctness with which the vibrations of the tuning-fork are felt when applied to a dull or a resonant area can be made by placing it first over the liver, then the lung, or abdominal cavity, of the experimenter. The tuning-fork is not a rival to percussion or palpation, but it will, I think, be found a useful accessory to the armamentarium of the physician and perhaps also of the surgeon. Recently I tried the tuning-fork in a case of syphilitic thickening of the meninges (cerebral) the results, though not decisive, were sufficient to make me believe in its utility in cases of tumours of the brain.

I am, Sirs, yours faithfully,

\section{G. S. R. STRITCH,}

Nov. 8th, 1902. Resident Medical Officer, Gover Hospital, Dublin.

\section{A POINT IN ARSENICAL POISONING.}

To the Editors of THE LANCET.

SiRs,-Twice in arsenical neuritis I have observed the hremoglobin collected in beads along the edge of the red blood corpuscle, not single specimens but numerous. At first glance the beads appear to be crenations of the corpuscle, but careful observation brings out the true nature. The beads were in both cases very dark and the blood from the finger was rather darker than usual. Arsenic is known as a blood poison and the above clinical observation may be extended to find more general conditions for the phenomenon. It can readily be seen why neuritis should occur and even a tendency to hæmorrhage, such as I noted concomitantly with this abnormal blood. It may be stated that except under the condition named the blood was absolutely normal and the bodily health was good. I have not observed this in a syphilitic case where arsenic was pushed to the extent of causing stomach troubles--to a slight extent-and the production of a white line on the gums. As I am not aware of any observations on this subject of a kindred nature it may be of interest to bring it under the notice of the profession. I am, Sirs, yours faithfully,

Southfields, S.W., Nov. 3rd, 1902. JoHN REID, M.D., M. A., C.M.

\section{NOTES FROM INDIA.}

\section{(From OUR Special CoRrespondent.)}

The Pasteur Institute-The Plague Epidemic.-1 Proposed Crematorium for Calcutta.

STEAdY progress has been made in the work of the Pasteur Institute for India. There was a total of 543 patients for the second year's work, or 222 more than in the preceding year. There were 215 European patients as against 146 last year, and 328 native patients as compared with 175 in the preceding year. It is satisfactory to find that the patients came from all parts of India. There were 185 from the United Provinces, 181 from the Punjab, 45 from Bengal, 20 from Bombay, 31 each from Madras and the Central Provinces, 10 from Assam, five from Kashmir, and four from Burmah. There were five deaths, all among native patients. Delay in attending for treatment proves very dangerous. The institute is receiving more financial support. Several local governments give annual grants and it is expected that the Government of India will also contribute. Private individuals gave Rs. 5134 out of the total incone of Rs. 20,946.
The plague returns for the past week indicate a slight check in the development of the epidemic. The deaths were 10,108 , as compared with 10,818 during the previous seven days, but this slight diminution is due to a fall in the number of deaths in the Bombay Presidency, where the local outbreaks have probably passed their maximum of mortality. In other parts of India there are ominous increases. The principal tigures published are: Bombay Presidency, 7057 deaths, as against 7780; Mysore State, 1056, as against 1122 ; United Provinces, 809, as against 736 ; the Punjab, 308, as against 210 ; Madras Presidency, 317, as against 385 ; Berar, 229, as against 148; Bombay city, 103, as against 101; and Bengal, 77, as against 52. Silence is maintained about the outbreak in Cawnpore. The disease has reappeared in Benares. The week's figures show the continued increase in Bengal, the United Provinces, and the Punjab. There is now no mistake about a further recrudescence in Bombay city, where the death-rate has risen to over 50 per 1000 . The recorded plague deaths do not account for the increase, and as this increase is returned chiefly under the heading "all other diseases" we must presume that a considerable number of plague deaths are undiscovered. The great inoculation scheme for the Punjab has begun well. Europeans have come forward first and large numbers of the natives have followed. It is evident, however, that the plague is rapidly increasing while inoculations have only just been commenced, and it is very doubtful whether sufficient numbers will be protected in time to have much effect on its epidemic development.

Active steps are being taken in Calcutta to establish a crematorium and a society is about to be formed on the lines of those in England. The subsoil of the city is so wet that ordinary burial, especially in the rainy seasons, is most objectionable and the necessity for disposal of the corpse as early as possible after death is likely to favour the practice of cremation. There is a growing feeling in Calcutta in favour of the establishment of a modern well-equipped crematorium and the prospects of the movement are better than they have ever been before. Notwithstanding three Hindu burning ghâts there is no place where non-Hindus can cremate their dead, which for a tropical city and the capital of India is nothing less than a scandal.

Oct. 16th.

\section{The Plague Epidemio. - Inoculation Scheme for the Punjab.- Sanitary Progress in Caloutta.}

The slight diminution in the plague mortality throughout India shown in last week's returns has proved only temporary. The deaths during the past seven days have risen in number from 10,108 to 10,750. For the corresponding week last year the plague deaths amounted to 8372 . Bombay city records 111 deaths, Bombay Presidency 7351, Karachi city 7, Madras Presidency 190, Bengal 111, United Provinces 1058, Punjab 278, Mysore 1139, Hyderabad 290, Berar 184, and Central India 200. These figures indicate the continued virulence of the epidemic in the oldest infected districts and a development in the central parts of India and the northwest. A revival is expected in Bombay city and in Bengal. It has been considered advisable to take precautions for the Delhi Durbar and from Nov, 1st all passengers by trains approaching Delhi will be examined. The futility of this measure has been shown over and over again and the Plague Commission has reported against it, but views once engraved on the official mind die hard.

rThe plague officers on the Bombay side as well as the regular service will be glad to hear that Colonel $W$. McConaghy, now principal medical officer of Sind, will succeed on Nov. 1st to the post of surgeon general for Bombay.

The great inoculation scheme for the Punjab is progressing favourably, even if slowly. 15,000 inoculations a week sounds large, but compared with the population it is trifling. 50,000 or even 100,000 a week will be required to make any impression if this province is attacked as severely as it was last year.

A recent review of the sanitary works in progress in Calcutta under the present municipality shows that active steps are being taken to make up for long-continued neglect. There are in hand the suburban drainage scheme and outfall works, the conversion of the present intermittent supply of filtered water to a constant one, the extension of the unfiltered water-supply, the erection of an additional refuse destructor, the provision of fresh markets and gowkhanahs, 